benefit of workers in other parts of the world. In the UK in 1960-5, according to Ashley, ${ }^{10}$ evidence suggested that "some $15 \%$ of males and $18 \%$ of females are subjected to appendicectomy." What are the proportions nowadays? What is the present situation in, say, the Hebrides compared with that in London? In 1942 operation frequency in pre-OCTU student candidates was eight times higher than that in non-student young men. ${ }^{11}$ Does a like disparity still prevail? Furthermore, in immigrant populations in London such as Caribbeans and Asians, what are the respective frequencies of operations among them? In the USA appendicitis incidence "has decreased $40 \%$ in 20 years, perhaps more"12; but from what rate to what rate?

We live in a time when the armamentarium for disease detection is far advanced and magnificent. It is therefore ironic that elementary information is almost completely lacking on a disease's precise frequency, the index of which, in a community, is more readily ascertainable than the making of an anthropometric measurement.

Human Biochemistry Research Unit,

South African Institute for Medical

Research,
Johannesburg, South Africa

A R P WALKER

Baragwanath Hospital,

Johannesburg, South Africa

Walker, A R P, et al, fournal of Postgraduate Medicine, 1973, 49, 243. 1973, 49, 243.
Panda, H O, Tropical and Geographical Medicine,
1975, 23, 354. Watson, W C, fournal of Tropical Medicine and
Hygiene, 1968, 71, 229.

Omigbo, w L, South African fournal of Surgery,

${ }_{6}^{5}$ Osman, A A, International Surgery, 1974, 59, 218. Royal College of Surgeons of Edinburgh, fournal of the Royal College of Surgeons of Edinburgh, 1978, 23, 369.
elley, E P, Journal of the American Medical Association, 1968, 206, 647 .

tion, 1968, 206, 647. Africa Ltd, Annual Report.
Goldfields of South A Johannesburg, 1977

United States Naval Medical Bulletin, 1949, 49, 1180.

${ }^{10}$ Ashley, D J P, Gut, 1967, 8, 533 .

1 Lunn-Rockliffe, W E C, British Medical fournal,

$1942,1,623$.
Mendeloff, A , in Fiber Deficiency and Colonic
Disorders, R W Reilly and J B Kirsner, $\mathrm{p} 145$. Disorders, R W Reilly and
Plenum, New York, 1975.

\section{Guar crispbread in the diabetic diet}

SIR,-We are naturally interested in the preliminary report by Drs $M$ Cohen and M I R Martin (3 March, p 616) of their study on the addition for three months of either a gel-forming fibre or bran or an unspecified placebo to the diet of obese "maturity-typeonset" diabetic outpatients, and thoroughly agree with their emphasis on the important need for long-term studies of dietary fibre supplements in diabetics. Hence we have already submitted for publication results on the first small group of diabetics taking a guar-supplemented diet continuously for six months, happily without obvious mineral deficiency.

We would like to make two main comments concerning their negative finding with guar gum. Firstly, as recently emphasised in correspondence elsewhere, ${ }^{1}$ gel-forming fibre is likely to be markedly effective in reducing postprandial blood glucose concentrations only when it is intimately mixed with the carbohydrate portion of the food-for example, guar gum in the bread mix before cooking or extra pectin mixed into marmalade. $^{2} 3$ We are uncertain how the guar gum was added to the diet in their study. Gel-forming fibre must be in the food, not on it, to be fully effective.

Secondly, short-term studies ${ }^{2-4}$ of gelforming fibre have all dealt with the reduction in postprandial (or postloading) glucose levels The principal postulated action of guar is to effect a reduced rate of absorption of nutrien from the small bowel without causing malab sorption. Apart from the effect on satiety, there is no a priori reason to expect from this a weight change or alteration in overnight fasting glucose concentrations. If they occur, they are likely to be secondary consequences of the main action. This is also why we have looked particularly at urinary glucose values, which are so susceptible to alterations in postprandia blood glucose levels.

Radcliffe Infirmary,
Oxford OX2 6HE

T DEREK R HOCKADAY

Department of the Regius
Professor of Medicine, Radcliffe Infirmary,
Oxford OX2 6HE

DAvid J A Jenkins

THOMAS M S WOLEVER RICHARD NINEHAM

University Laboratory of Physiology,
Oxford OX1 3QT

RODNEY TAYLOR

Department of Gastroenterology,

Central Middlesex Hospital

Metabolic Unit,

Nuffield Orthopaedic Centre,

1 Jenkins, D J A, et al, Lancet, 1979, 1, 434.

Jenkins, D J A, et al, Annals of Internal Medicine, 1977, 86, 20.

3 Jenkins, D J A, et al, Lancet, 1976, 2, 172.

Jenkins, D J A, et al, British Medical fournal, 1978, 1, 1392

Heaton, K W, Lancet, 1973, 2, 1418.

\section{Heart rate in diabetes mellitus}

SIR,-There is great attraction in simplifying measurements of autonomic function. Dr G Sundkvist and others (7 April, p 924) propose a new test of heart rate variation-the "E:I ratio," which they say "seems to be as accurate as traditional tests for autonomic function and easier to perform." Although they may be right in this claim, the interpretation of the results that they have actually presented must be viewed with some caution.

They have shown clearly that the $R-R$ interval is shortened in their diabetics with sensory neuropathy, and that $R-R$ interval variation is also reduced. They have also shown that the E:I ratio is lower in the same subjects. But what evidence have they that the $E$ :I ratio in these subjects is not just a function of a faster resting heart rate? None of them had any clinical symptoms of autonomic neuropathy, and although diabetics as a group have a faster heart rate than normal subjects its relation to autonomic neuropathy is obscure.

D J EwING

Department of Medicine,

Royal Infirmary,

** We sent a copy of this letter to the authors, whose reply is printed below.-ED, $B M \mathcal{H}$.

SIR,-Dr Ewing has raised the question whether the reason for the observed abnormalities in E:I ratio ( 1.10 or below) among our diabetics with sensory neuropathy is due to the increase of the resting heart rate. Earlier studies, ${ }^{1}$ however, have shown that the heart normally is inhibited by vagal tone, and defective nervous function gives rise to tachycardia that is easily demonstrated by atropin experiments. The influence of deep breathing on heart rate (beat-to-beat variation) has also been proved to be dependent on normal vagal function. ${ }^{2}$ Thus deficient beatto-beat variation indicates vagal dysfunction and the same mechanism explains the increased heart rate in such patients. It has also been stated $^{3}$ that slight impairment in beat-to-beat variation could be the earliest manifestation of neuropathy.

Our study clearly demonstrated that estimation of the $E: I$ ratio was equivalent to the method used in these previous studies. ${ }^{1-3}$ Therefore our patients probably have vagal neuropathy, which could explain their ncreased heart rate at rest. In diabetics with abnormal $\mathrm{E}: \mathrm{I}$ values correlation analysis did not show a significant $r$ value $(0 \cdot 19)$ between the $R-R$ intervals at rest and $E: I$ ratios. Furthermore, no significant correlation was found in a recent study ${ }^{4}$ between changes in heart rate in response to a single deep breath and mean resting supine heart rate. These results seem to contradict the idea that the increased heart rate gives the abnormal ratio.

In conclusion, our belief is that the abnormal $\mathrm{E}: \mathrm{I}$ ratios are manifestations of early autonomic neuropathy in the investigated patients. But the final answer to the controversy will, of course, come during the next years when the patients are followed up.

GÖRAN SUNDKVIST

Department of Internal Medicine,

University of Lund,

Allmänna Sjukhuset,

${ }^{1}$ Lloyd-Mostyn, R H, and Watkins, P J, British Medical fournal, 1975, 3, 15.

Wheeler, T, and Watkins, P J, British Medical fournal,

$1973,4,584$.
Page, $M$, and Watkins, $P$ J, Clinics in Endocrinology

and Metabolism, 1977, 6, 377.
${ }^{4}$ Bennet, $\mathrm{T}$, et al, Diabetes, 1978, 27, 1167.

\section{Heart rate variation in tetraplegic} patients

SIR,-Having read the article written by Dr G Sundkvist and others (7 April, p 924) and being very interested in the analyses of heart rate variations as an easy method for the evaluation of autonomic nervous disturbances, we would like to add our experience.

Recently Neubauer and Gundersen ${ }^{1}$ have proved that in patients with multiple sclerosis, in whom the autonomic nervous system can be involved, the mean square successive difference (MSSD) and the usual standard deviation (SD) of the R-R successive intervals in the ECG show a reduction comparable to that observed in long-term diabetics with autonomic abnormalities. We are now studying the autonomic disturbances in a group of 15 tetraplegic patients admitted to our intensive care unit because of severe respiratory failure. Ages range from 19 to 45 years, seven patients being women and eight men. The underlying diseases are a traumatic injury of the spinal cord in 12 patients, a cervical tumour in one, Heine-Medine disease in one, and cervical myelopathy in the last. The level of tetraplegia is between $\mathrm{C} 4$ and $\mathrm{C} 6$. In all these patients, as in 14 members of the medical staff (seven women and seven men) with ages ranging from 19 to 35 years, an ECG was obtained during a period of three minutes with a paper speed of $50 \mathrm{~mm}$ per second, measuring the lengths in millimetres of at least 150 consecutive $R-R$ intervals. The statistical analyses of these two groups show an MSSD and SD of 1.36 and 1.77 respectively for the control group and 0.40 and 0.60 for the group of patients. This means a statistically significant difference at the level of $\mathrm{P}<0.00001$ when a comparison of MSSD and SD for both groups is made. We consider the measure- 
ment of beat-to-beat variation a simple and useful test for the evaluation of cardiac denervation in these patients.

Cardiorespiratory arrest is a common complication in this kind of patient as it is in the diabetic patients with autonomic neuropathy, ${ }^{2}$ and some of the unexplained sudden deaths are likely to be related to the existence of functional abnormalities of the autonomic nervous system.

The function of the autonomic nervous system in other diseases is likely to be easily evaluated by the measurement of beat-to-beat variation. We have found very suggestive results in patients with the Guillain-Barré syndrome even though the number of cases studied to date is not large enough for statistical treatment.

J C Frisón

L SÁNCHEZ MASSA

A GARNACHO

V GiMENo

\author{
Intensive Care Unit and \\ Data Processing Centre, \\ Ciudad Sanitaria \\ 1 Neubauer, B, and Gundersen, H J C, fournal of \\ Neurology, Neurosurgery, and Psychiatry, 1978, 41, \\ 2 Page, M M, and Watkins, P J, Lancet, 1978, 1, 14.
}

\section{Safety of piped medical gases and electromedical equipment}

SIR,-I refer to Dr C S Ward's letter on the safety of piped medical gases (14 April, p 1019) and would like to offer the following comments to supplement his views.

The new British Standard for medical gas pipeline systems, terminal units hose assemblies, and connections to medical equipment was published in December 1978 (BS 5682). The terminal units $\mathrm{Dr}$ Ward refers to are the British Oxygen Company Mk 4 Units. These were in production before the issue of the British Standard, but it is understood that they are generally in compliance with its requirements. There are and will continue to be other outlets available which are to the BS 5682 requirements.

So far as I am aware, there has not been an accident with medical gases which has been attributable to the fixed portion of the systems - that is, that part of the system from the gas source to the terminal unit permanently installed in the building fabric. The BS requirements provide for a system that is inherently safe, when the components covered are installed in the manner demanded by Hospital Technical Memorandum No 22, in that they ensure the non-interchangeability of probe-terminal unit and give the additional convenience that the terminal units are now to be specified as having an individual isolation valve (preferably automatic) that will allow servicing without affecting the operation of other units. This feature is of significant importance in the operation of the "permit to work" system that is now the requirement for all work, from minor servicing to major modifications or additions, to any medical gas pipeline system. The isolating valves and other alterations to which Dr Ward refers are also aimed at the improvement of the system to enable localised servicing to be carried out without disruption of the supplies to other areas.

The question of communication of intention is one to which there is probably not a universal solution in regard to the proposals to upgrade any installation. However, with the introduction of a permit to work system, the medical officer or nurse in charge of the management of a unit must be made aware of any proposals before work can be put in hand. This is part of the permit to work system and requires that a signature be obtained from one or other to say that the MO or nurse is aware of the nature and the expected duration of the work. If any clinician is not satisfied he can obviously decline to give such a signature. This might in the immediate instance inconvenience and embarrass the engineer but would ensure that the proper consultation took place for future proposals.

\section{T L TOMPKIN}

Yorkshire Regional Health Authority,

SIR,-I must take issue with Dr C S Ward in his letter (14 April, p 1019) concerning the safety of piped medical gases. It is the interface between hospital clinician and engineer referred to in the third paragraph that is the point on which I disagree.

Following the report on the Shewan incident, ${ }^{1}$ hospitals in this region have been endeavouring to arrive at a workable arrangement regarding the division of responsibility between those who use equipment and those who service it. As Dr Ward states, the final responsibility for administering treatment rests with the doctor concerned. However, in busy theatres when the same anaesthetic machine is used repeatedly during a day it is not considered necessary to perform the "one hose and tug" tests to identify gas line connection to rotameters.

We have been advised by our defence organisation that a nominated doctor responsible for the equipment serviceability in our theatres would be unwise, leading to personal crucifixion in the event of an accident. I wonder whether Dr Ward implies the name "engineering liaison officer" for the member of staff who talks to the engineering department servicing the hospital medical equipment.

\section{Department of Anaesthesia,}

Good Hope General Hospital

Sutton Coldfield

${ }^{1}$ Department of Health and Social Security, HN
(Hazard) $77 / 19$. London, DHSS, 1977 .

G A H Heaney

\section{Hypnosis}

SIR,-The letter from Dr H G Kinnell (17 March, p 751) suggests that he has fallen into the common trap of those unwilling to consider the phenomena of the hypnotic state. Hypnosis acts by achieving an altered state of awareness, in which can be produced distortions of emotion, sensation, image, and time. " If this is due to "waking suggestion,"2 be it so. The fact remains that a large body of medical experts throughout the world would confirm the effectiveness of the proper clinical application of hypnotherapy.

Dr Kinnell is correct when he quotes me as saying that the use of hypnosis may on occasion be harmful. ${ }^{3}$ But the statement is taken out of context since it referred to "its use by unqualified persons for the purposes of entertainment or by lay therapists." Would anyone dispute the obvious restrictions on the improper use of psychotropic medication?
Nevertheless, hypnosis is not a panacea for all ills and certainly not a panacea for all psychiatric ills. But that it has a definite place in the psychotherapeutic armamentarium as an additional weapon for the treatment of certain neurotic symptoms is beyond doubt. As with other disciplines in psychiatry, it must be used selectively and only by the very experienced.

In 1784 a French Commission of Inquiry concluded that the phenomena could be explained only by the imagination and imitation of the subject. Nearly 200 years later, research has shown the neurophysiology of the hypnotic state to be quite a little more.4 Today most serious therapists will subscribe to the objectives of the new section of medical and dental hypnosis of the Royal Society of Medicine-namely, to extend the knowledge of the hypnotic state, to investigate further its neurophysiology, and to promote interest in its clinical use. ${ }^{5}$

The implications contained in your leading article on hypnosis in the NHS (7 October, p 978) were fully justified, and the findings of the Psychological Medicine Group Subcommittee of the $\mathrm{BMA}^{6}$ are worthy of implementation.

D WAXMAN
President, Section of
Medical and Dental Hypnosis,
Royal Society of Medicine

Central Middlesex Hospital, 1 Waxman, D, fournal of the Royal Society of Medicine,
1979, 32, 168. Costello, C G, Psychology for Psychiatrists, p 121.
Oxford, Pergamon, 1966.

Waxman, D, British Medical fournal, 1978, 2, 571. Wyke, B D, Proceedings of the Dental and Medical Society for the Study of Hypnosis, London, 1960. Royal Society of Medicine, Regulations of the New Section of Medical and Dental Hypnosis. London, RSM, 1978

Committee of the Psychological Medicine Group Committee of the British Medical Association, 190 .

\section{Homoeopathic medicine}

SIR,-Dr R S Walker (28 April, p 1147), referring to my book Homoeopathy, claims that we speak a different language from that of our allopathic colleagues. It is true that every branch of science has its own peculiar jargon, and we are no exception to the rule. But when evaluating our clinical results we are as strictly impartial as are our orthodox counterparts.

His view that we have "little insight into the powers of suggestion" is a mistaken one. We are always aware of the possibility of mental suggestion. But in practice we find that the creatures most sensitive to homoeopathic potencies are animals and infants. Can suggestion achieve immunity to infection ? Consider the following incidents. ${ }^{1}$

In the mid-1930s I gave a Schick-positive girl a homoeopathic potency (Diphtherinum 200). Ten days later she was still Schick positive. Two weeks later she was Schick negative, and her follow-up tests remained negative.

In those days I was the appointed MO to the Rochdale Children's Holiday Home in Lytham St Annes. A child in the home developed diphtheria. Dr Litt, the MOH, sent her to hospital, where she died. In the meantime I had given Diphtherinum 200 to every inmate of the home. Another case occurred, and Matron implored me to let her keep the child out of hospital. I temporised by taking a swab and delaying notification. The swab was, as expected, positive; but the throat looked 